\title{
Successful Ovarian Vitrification and Back-Transplantation to Preserve Fertility in a Patient Requiring Chemotherapy for Malignant Lymphoma
}

Iwaho Kikuchi ${ }^{1 *}$, Noriko Kagawa ${ }^{2}$, Sherman Silber ${ }^{3}$, Yasushi Isobe ${ }^{4}$, Masashige Kuwayama ${ }^{2}$ and Satoru Takeda ${ }^{1}$

${ }^{1}$ Department of Obstetrics and Gynecology, Juntendo University Faculty of Medicine, Tokyo, Japan

${ }^{2}$ Repro-Support Medical Research Centre, Tokyo, Japan

${ }^{3}$ Infertility Center of St. Louis, St. Luke's Hospital, St. Louis, Missouri, USA

${ }^{4}$ Department of Hematology and Medical Oncology, St. Marianna School of Medicine, Kawasaki, Japan

\begin{abstract}
For women with hematologic malignancy anticipating chemotherapy or radio therapy but wishing to preserve fertility, it is preferable that recovery from oophorectomy be as rapid as possible. Considering Reduced-Port Surgery (RPS) to be potentially suitable for such patients, we used RPS for a patient with malignant lymphoma scheduled for pre-bone marrow transplantation chemotherapy. The patient was a 28 -year-old woman, gravida 0 , who had requested fertility preservation. Thus, with ethics committee approval, the left ovary was removed by RPS, and ovarian cortex with primordial ovarian follicles was cryopreserved by vitrification. The cortex was divided into 12 pieces, $1 \mathrm{~cm} \times 1 \mathrm{~cm} \times 1 \mathrm{~mm}$ each, placed in a container, and stored in liquid nitrogen. The patient's post-bone marrow transplantation course was good. Because she was judged to have lost ovarian function, ovarian back-transplantation was performed by RPS. The cortex of the remaining right ovary was removed with a laparoscopic cold knife and scissors while heparin saline was instilled to maintain blood flow and a $2 \mathrm{~cm} \times 1 \mathrm{~cm}$ base was created. Two thawed ovarian cortex pieces were laparoscopically sewed to the base with 5-0 absorbable sutures. By postoperative day 173 , the ovarian follicle had increased to $10 \mathrm{~mm}$ in diameter, and the patient's estradiol level had risen to $101 \mathrm{pg} / \mathrm{ml}$, suggesting recovery of ovarian function. Our experience in this lymphoma case suggests that ovarian cryopreservation and back-transplantation for fertility preservation can be performed safely by RPS and is a viable option for selected patients anticipating chemotherapy and bone marrow transplantation for hematologic malignancy.
\end{abstract}

Keywords: Lymphoma; Bone marrow transplantation; Chemotherapy; Reduced-Port Laparoscopic surgery; Fertility preservation; Vitrification; Cryopreservation; Ovarian transplantation

Abbreviation: RPS: Reduced-Port Surgery

\section{Introduction}

In 2004, Donnez et al. [1] removed ovarian tissue from a patient anticipating chemotherapy for Hodgkin's disease and cryopreserved the cortical tissue to preserve fertility. After treatment of the primary disease, the tissue was transplanted back into the patient, and spontaneous pregnancy was achieved [1]. The slow freezing method was used for cryopreservation in the early days, but vitrification-based cryopreservation, which provides a higher tissue survival rate, has since been developed $[2,3]$. We have reported ovarian function after backtransplantation of a vitrified-thawed ovary [4].

Reduced-Port Surgery (RPS) has attracted attention in recent years as a less invasive procedure than conventional laparoscopic surgery [510]. For patients scheduled to undergo chemotherapy or radiotherapy, it is preferable that recovery from oophorectomy be as rapid as possible; therefore, we considered RPS to be potentially suitable for these patients, and we have reported six cases of fertility preservation achieved by RPS [11].

We herein provide the first report of recovery of ovarian function achieved via RPS tissue harvest and RPS back-transplantation of vitrified ovarian tissue. The patient, a childbearing age woman with malignant lymphoma, was treated by us before and after chemotherapy.

\section{Case Report}

A 28-year-old woman, gravida 0 , had been diagnosed with malignant lymphoma (peripheral T-cell lymphoma, stage IV). Anticipating chemotherapy and bone-marrow transplantation, she requested fertility preservation, which we performed as described in detail below. The chemotherapy comprised a combination of Methotrexate, Ifosfamide, L-asparaginase, and Dexamethasone (MILD) $[12,13]$ under the following regimen: IFM $\left(1000 \mathrm{mg} / \mathrm{m}^{2}\right.$, by intravenous infusion over 30 minutes) and DEX (20 mg, by intravenous infusion over 4 hours) on days 1-3; and MTX ( $2 \mathrm{~g} / \mathrm{m}^{2}$, by intravenous infusion over 6 hours) on day 4; Escherichia coli-derived l-Asp (Leunase; Kyowa Hakko Kirin Inc., Tokyo, Japan) $\left(6000 \mathrm{KU} / \mathrm{m}^{2}\right.$, by intravenous infusion over 60 minutes) on days 5,7 , and 9 . The initial administration of 1-Asp (on day 5) and leucovorin rescue were started 24 hours after completion of the MTX infusion. The patient underwent pretreatment for bone marrow transplantation after chemotherapy for the malignant lymphoma. Ovarian failure resulted. Her serum Luteinizing Hormone (LH), Follicle-Stimulating Hormone (FSH), and estradiol levels decreased to $88.2 \mathrm{miu} / \mathrm{ml}, 171.5 \mathrm{miu} / \mathrm{ml}$, and less than $5 \mathrm{pg} / \mathrm{ml}$, respectively. Because of the lost ovarian function, the patient was given female hormone replacement therapy delivered via adhesive skin patches.

As noted above, the patient had requested fertility preservation. This was 2 years before the start of treatment. Thus, with ethics committee approval, her left ovary was removed by means of RPS, a less invasive

*Corresponding author: Iwaho Kikuchi, Department of Obstetrics and Gynecology, Juntendo University School of Medicine, Hongo 2-1-1, Bunkyo-ku, Tokyo 113-8421, Japan, Tel: +81-3-3813-3111; Fax: +81-3-5689-7460; E-mail: kikuchiban@hotmail.com

Received December 03, 2013; Accepted January 02, 2014; Published January 05, 2014

Citation: Kikuchi I, Kagawa N, Silber S, Isobe Y, Kuwayama M, et al. (2014) Successful Ovarian Vitrification and Back-Transplantation to Preserve Fertility in a Patient Requiring Chemotherapy for Malignant Lymphoma. J Blood Lymph 4: 116. doi:10.4172/2165-7831.1000116

Copyright: @ 2014 Kikuchi I, et al. This is an open-access article distributed under the terms of the Creative Commons Attribution License, which permits unrestricted use, distribution, and reproduction in any medium, provided the original author and source are credited. 
procedure than routine laparoscope-assisted surgery, and ovarian cortical tissue with primordial ovarian follicles was cryopreserved by our previously reported method [11]. Briefly, the ovarian cortex was divided into 12 pieces, each $1 \mathrm{~cm} \times 1 \mathrm{~cm} \times 1 \mathrm{~mm}$, placed in a plate container, and stored in liquid nitrogen [2,11-13].

The patient's post-bone marrow transplantation course was good. Because she received the bone marrow from her brother, her progress was evaluated by Fluorescent in Situ Hybridization (FISH) with X-and Y-chromosome probes. Results of the FISH analysis on Days 26, 28, and 88 were XX 0.0\%, XY 99.8\%; XX 0.2\%, XY 99.8\%; XX 0.0\%, XY 93.2\%, and XYY 6.4\%, respectively. It was therefore confirmed that the cells of recipient origin were fully eliminated by Day 88 . The patient showed a slight skin rash as evidence of graft versus host disease, but steroid administration was not necessary.

From an internal medicine perspective, back-transplantation of the patient's ovarian tissue was considered feasible. Moreover, the patient desired ovarian transplantation, and the frozen-thawed ovarian capsule tissues were thus retransplanted. Prior to back-transplantation, one piece was thawed and pathologically examined, and absence of tumor cell invasion was confirmed.

Back-transplantation was performed by means of RPS. The cortex of the remaining right ovary was removed with a laparoscopic cold knife and scissors without an electric knife while heparin saline was instilled to maintain constant blood flow. A base, $2 \mathrm{~cm} \times 1 \mathrm{~cm}$, was created on the right ovary (Figure 1). Two thawed ovarian capsule pieces were laparoscopically sewed to the base with 5-0 absorbable sutures (Figure 2). Because fine suturing was required, an Olympus flexible scope providing high definition imaging was used. The assistant controlled the scope, placing its tip between the needle carrier and forceps, and a stable view was obtained [14]. The operative time was 2 hours 21 minutes, and the estimated blood loss was $50 \mathrm{ml}$; thus, the patient was discharged on the day after surgery. At approximately 4.5 months (postoperative day 138), a 7-mm ovarian follicle was detected by transvaginal ultrasonography. In addition, the patient's estradiol level had risen to $94 \mathrm{pg} / \mathrm{ml}$. By postoperative day 173 , the ovarian follicle had reached $10 \mathrm{~mm}$ in diameter (Figure 3) without ovarian stimulation, and the serum estradiol level had risen to $101 \mathrm{pg} / \mathrm{ml}$. The increase in estradiol and the ovarian follicle growth suggested recovery of ovarian function. The patient has decided to postpone pregnancy but requested ongoing follow-up.

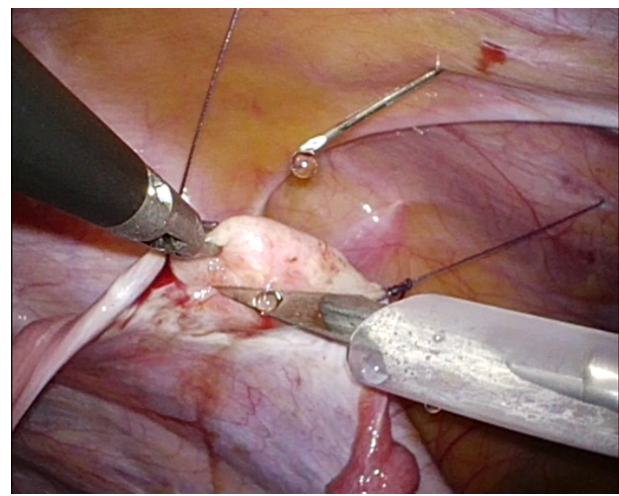

Figure 1: The cortex of the remaining right ovary was removed with a laparoscopic cold knife and scissors while heparin saline was instilled to maintain blood flow, and a base, $2 \mathrm{~cm} \times 1 \mathrm{~cm}$ in size, was created on the remaining ovary.

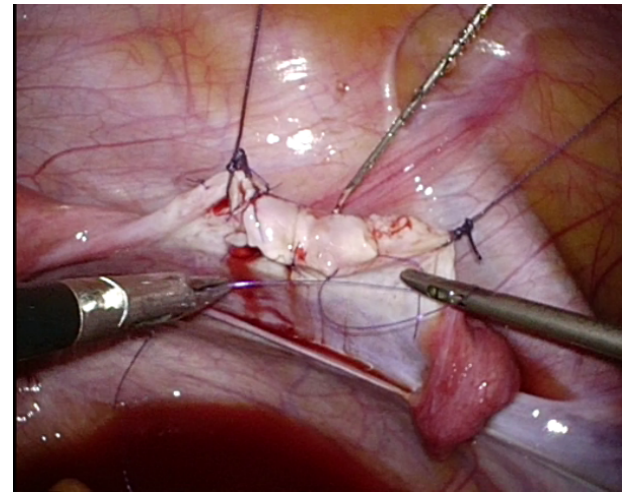

Figure 2: Two thawed ovarian capsule pieces were laparoscopically sewed to the base with 5-0 absorbable sutures.
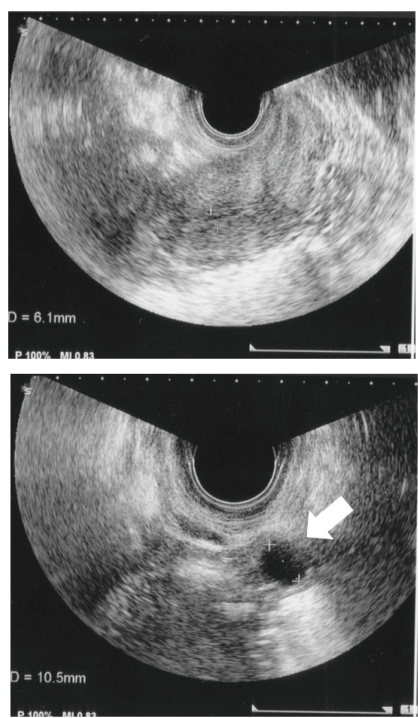

Figure 3: Transvaginal ultrasonographic examination on postoperative day 173 revealed that the ovarian follicle had reached $10 \mathrm{~mm}$ in diameter (white arrow). The serum estradiol level had risen to $101 \mathrm{pg} / \mathrm{ml}$.

\section{Discussion}

This is believed to be the first case of ovarian vitrification-based cryopreservation with ovarian capsule back-transplantation and the first reported use of RPS as a grafting technique in a patient diagnosed and treated for a malignant tumor. Candidate patients are scheduled to undergo chemotherapy, and it is desirable that treatment of the primary disease be started as early as possible. For this reason and since the report by Donnez et al. [1] oophorectomy has generally been performed laparoscopically. We introduced the even less invasive single-port surgery, which has attracted attention in recent years, and we have used this strategy for oophorectomy aimed at cryopreservation of the ovary [14].

Although most reports of ovarian tissue cryopreservation were of the slow freezing method, vitrification is more suitable than slow freezing for frozen storage of relatively large tissue samples, and the cell survival rate is high $[3,4,15]$. Transplantation of large tissues, however, requires suture manipulation. In our case, an operative procedure paralleling microscopically controlled surgery was performed with a high definition scope. Thus, transplant surgery was successfully 
Citation: Kikuchi I, Kagawa N, Silber S, Isobe Y, Kuwayama M, et al. (2014) Successful Ovarian Vitrification and Back-Transplantation to Preserve Fertility in a Patient Requiring Chemotherapy for Malignant Lymphoma. J Blood Lymph 4: 116. doi:10.4172/2165-7831.1000116

Page 3 of 3

performed as a minimally invasive procedure by means of RPS. Our patient's long-term clinical course is yet unknown, but we call attention to our RPS procedure and results thus far in the hope that this approach will aid women concerned with loss of ovarian function due to chemotherapy.

\section{Conclusion}

Our experience in this case suggests that ovarian cryopreservation and back-transplantation for fertility preservation can be performed safely by RPS and is a viable option for selected patients anticipating chemotherapy and bone marrow transplantation for hematologic malignancy.

\section{References}

1. Donnez J, Dolmans MM, Demylle D, Jadoul P, Pirard C, et al. (2004) Livebirth after orthotopic transplantation of cryopreserved ovarian tissue. Lancet 364 $1405-1410$.

2. Kagawa N, Silber S, Kuwayama M (2009) Successful vitrification of bovine and human ovarian tissue. Reprod Biomed Online 18: 568-577.

3. Keros V, Xella S, Hultenby K, Pettersson K, Sheikhi M, et al. (2009) Vitrification versus controlled-rate freezing in cryopreservation of human ovarian tissue. Hum Reprod 24: 1670-1683.

4. Silber S, Kagawa N, Kuwayama M, Gosden R (2010) Duration of fertility after fresh and frozen ovary transplantation. Fertil Steril 94: 2191-2196.

5. Steinemann DC, Raptis DA, Lurje G, Oberkofler CE, Oberkofler CE, et al (2011) Cosmesis and body image after single-port laparoscopic or conventiona laparoscopic cholecystectomy: a multicenter double blinded randomised controlled trial (SPOCC-trial). BMC Surg 11: 24.

6. Curcillo PG 2nd, Podolsky ER, King SA (2011) The road to reduced port surgery: from single big incisions to single small incisions, and beyond. World J Surg 35: 1526-1531.

7. Romanelli JR, Earle DB (2009) Single-port laparoscopic surgery: an overview. Surg Endosc 23: 1419-1427.

8. Uppal S, Frumovitz M, Escobar P, Ramirez PT (2011) Laparoendoscopic single-site surgery in gynecology: review of literature and available technology. J Minim Invasive Gynecol 18: 12-23.

9. Escobar PF, Starks D, Fader AN, Catenacci M, Falcone T (2010) Laparoendoscopic single-site and natural orifice surgery in gynecology. Fertil Steril 94: 2497-2502

10. Froghi F, Sodergren MH, Darzi A, Paraskeva P (2010) Single-incision Laparoscopic Surgery (SILS) in general surgery: a review of current practice. Surg Laparosc Endosc Percutan Tech 20: 191-204.

11. Kikuchi I, Kagawa N, Silber S, Kuwayama M, Takehara Y, et al. (2013) Oophorectomy for fertility preservation via reduced-port laparoscopic surgery. Surg Innov 20: 219-224.

12. Tsukune $Y$, Isobe $Y$, Yasuda H, Shimizu S, Katsuoka Y, et al. (2010) Activity and safety of combination chemotherapy with methotrexate, ifosfamide I-asparaginase and dexamethasone (MILD) for refractory lymphoid malignancies: a pilot study. Eur J Haematol 84: 310-315.

13. Isobe $\mathrm{Y}$, Aritaka N, Setoguchi $\mathrm{Y}$, Ito $\mathrm{Y}$, Kimura H, et al. (2012) T/NK cell type chronic active Epstein-Barr virus disease in adults: an underlying condition for Epstein-Barr virus-associated T/NK-cell lymphoma. J Clin Pathol 65: 278-282.

14. Kikuchi I, Kumakiri J, Kuroda K, Matsuoka S, Kitade M, et al. (2009) A nove modification of traditional 2-port laparoscopic surgery using a 5-mm flexible scope. J Minim Invasive Gynecol 16: 734-738.

15. Suzuki N, Hashimoto S, Igarashi S, Takae S, Yamanaka M, et al. (2012) Assessment of long-term function of heterotopic transplants of vitrified ovarian tissue in cynomolgus monkeys. Hum Reprod 27: 2420-2429. 